IFAS Extension

\title{
Red-tailed Flesh Fly, Sarcophaga haemorrhoidalis (Fallén) (Insecta: Diptera: Sarcophagidae) ${ }^{1}$
}

\author{
Angelique Showman and C. Roxanne Connelly ${ }^{2}$
}

\section{Introduction}

Sarcophaga haemorrhoidalis (Fallén), commonly known as the red-tailed flesh fly, is a member of the family Sarcrophagidae, the flesh flies. Flesh flies are calyptrates possessing well-developed lower calypteres, which are associated with the wings. The larvae of $S$. haemorrhoidalis invade carcasses that are in the early to advanced stages of decomposition, often arriving as early as blow flies (family Calliphoridae) (Byrd 1998-2011). Red-tailed flesh flies are considered opportunistic feeders on carrion, and primarily feed on human and animal waste (Madubunyi 1986). The flesh flies are an important family of insects in forensic entomology, a discipline that focuses on arthropods and arthropod behavior as evidence in legal and criminal matters.

\section{Distribution}

Sarcophaga haemorrhoidalis is distributed throughout the world and is frequently associated with human and animal remains both in Canada and the United States (Byrd \& Castner 2001). This species can be found year-round in the southern part of the United States (Byrd 1998-2011) and is absent only from subarctic areas (Madubunyi 1986).

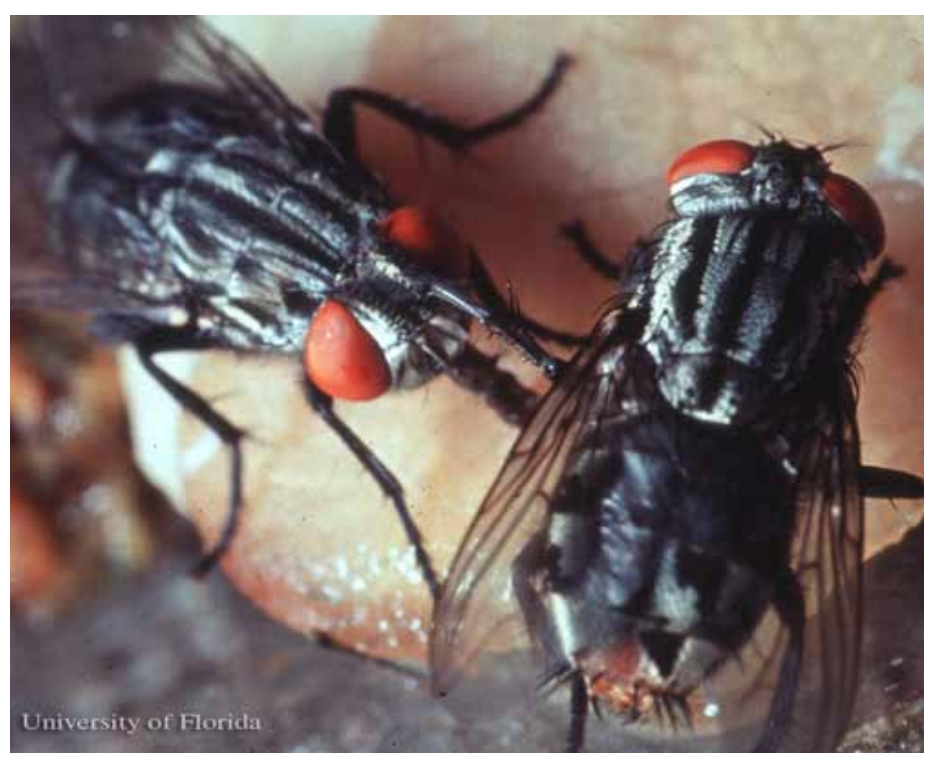

Figure 1. Dorsal view of adult Sarcophaga haemorrhoidalis (Fallén), the red-tailed flesh fly.

Credits: Jerry Butler, University of Florida

\section{Description}

\section{Adults}

The adults of S. haemorrhoidalis resemble house flies (Family Muscidae) in their general appearance, but are larger and more robust, ranging from 8 to $14 \mathrm{~mm}$ in length. Sarcophagid flies can also be differentiated from muscid flies by the presence of three dark longitudinal stripes on the thorax instead of four. Adult S. haemorrhoidalis possess black-colored bodies covered with a whitish powder-like

1. This document is EENY-495 one of a series of Featured Creatures from the Entomology and Nematology Department, Florida Cooperative Extension Service, Institute of Food and Agricultural Sciences, University of Florida. Published: August 2011. This document is also available on Featured Creatures website at http://entomology.ifas.ufl.edu/creatures. Please visit the EDIS website at http://edis.ifas.ufl.edu.

2. Angelique Showman, graduate student; and C. Roxanne Connelly, associate professor; Entomology and Nematology Department, Cooperative Extension Service, Institute of Food and Agricultural Sciences, University of Florida, Gainesville, FL 32611. 
substance that gives them a grayish tint. Their abdomen has a distinct checkerboard-like pattern. The common name of this species comes from the presence of red-colored external genitalia visible at the terminal end of the abdomen, though other sarcophagid species may also have this feature (Byrd \& Castner 2001). Like many other sarcophagids, they have large compound eyes, and the aristae of the antennae are long and are plumose at the base (Byrd \& Castner 2001). The adult head has a row of frontal bristles near the enlarged median vertical area. The mouthparts are designed for lapping liquid media from sugar and decomposing sources. The dorsal mesothorax also possesses a row of longitudinal bristles; however, the bristles anterior to the scutum are rudimentary if present at all.

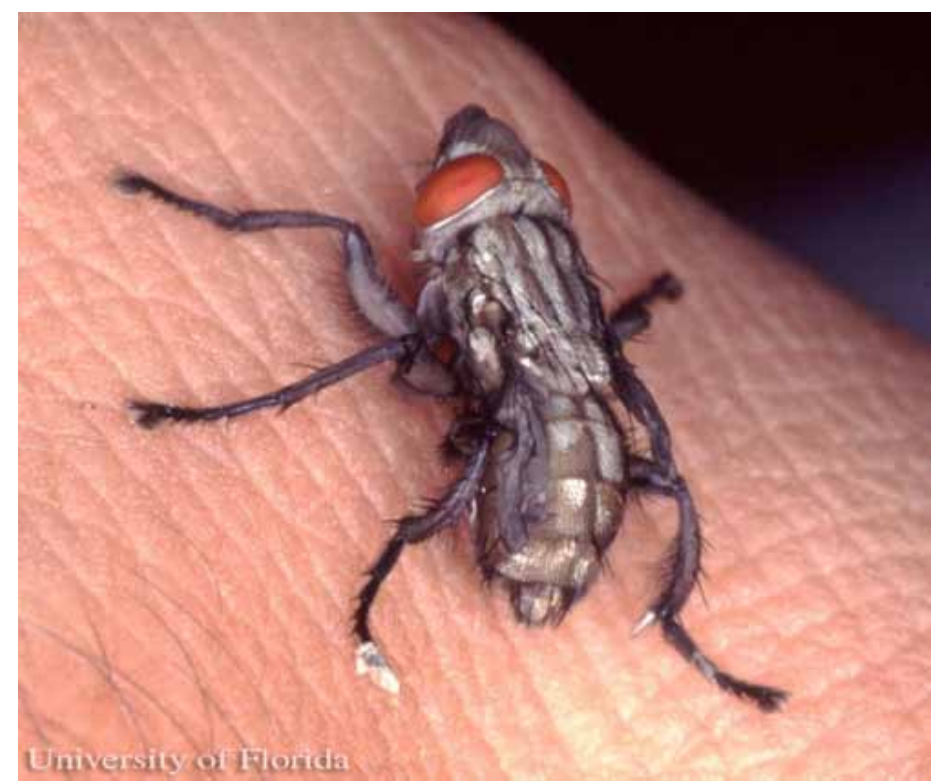

Figure 2. Dorso-lateral view of an adult Sarcophaga haemorrhoidalis (Fallén), the red-tailed flesh fly.

Credits: Jerry Butler, University of Florida

\section{Eggs}

The eggs of S. haemorrhoidalis range in size from 0.5 to 3.5 $\mathrm{mm}$ long and 0.12 to $0.8 \mathrm{~mm}$ wide.

\section{Larvae}

The larvae are white to slightly yellow in color, and wormlike with a pointed head. The larvae are comparatively larger than other fly larvae, reaching 10 to $22 \mathrm{~mm}$ in length prior to pupation (Baker et al. 1986). Each instar has a pair of strong mandibles for tearing and eating flesh and other food substrates (Mullen \& Durden 2002). Spiracles on the posterior end are located in a cavity that is fringed in triangular-shaped tubercles. Like other fly species, the number of slits in each spiracle are nearly parallel to each other and the larval midline, and are used to determine the age, or larval instar, of the maggot (Byrd \& Castner 2001).

\section{Pupae}

The pupae are reddish-orange to dark brown and change colors as they age.

\section{Life Cycle}

Like other calyptrate flies, S. haemorrhoidalis undergoes complete metamorphosis through four life stages: egg, larva, pupa, and adult. The complete life cycle takes approximately 23 days under laboratory conditions from 1st instar larvae to adult (Madubunyi 1986). Like other sarcophagids, females engage in larviposition, wherein the eggs hatch inside the female and are then deposited as first instar maggots on decomposing flesh or excrement (Byrd \& Castner 2001). Females have been known to larviposit on surface material above shallowly buried corpses where the larvae then tunnel through the burial material to get to the decomposing body (National Library of Medicine 2006).

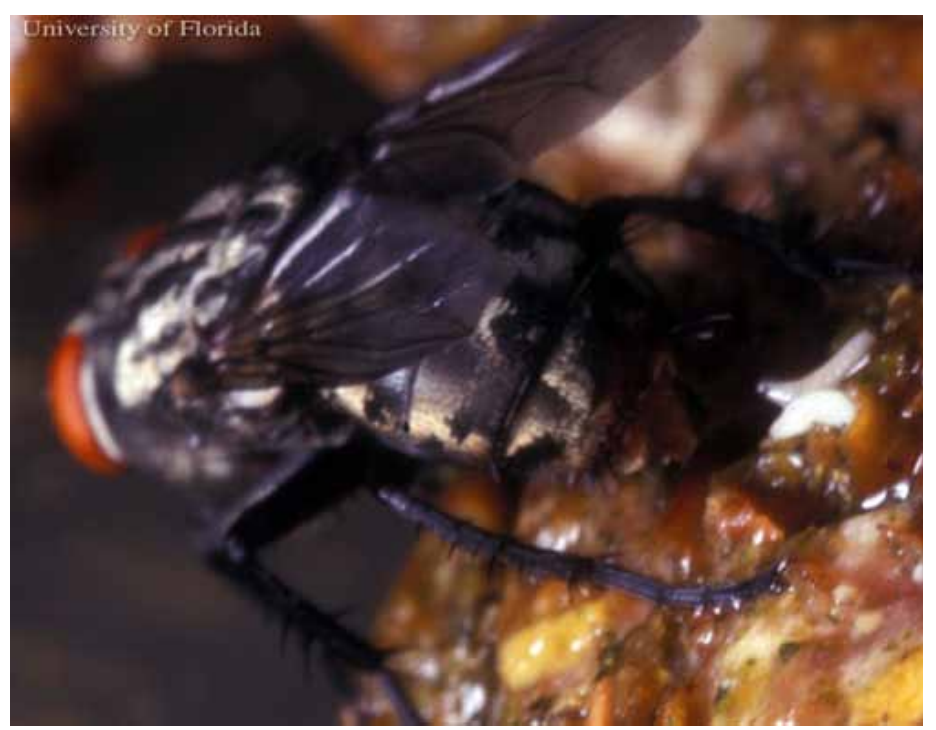

Figure 3. Adult female Sarcophaga haemorrhoidalis (Fallén), the redtailed flesh fly, depositing first instar maggots (white larvae, right). Credits: Jerry Butler, University of Florida

Larvae prefer moist environments and can even survive in semi-aquatic conditions (Byrd 1998-2011). On average, larvae complete three instars within five to six days before pupating (Smith \& Whitman 1992), though other studies have shown larval duration to be seven to nine days at $25 \mathrm{C}^{\circ}$ (Pape 1996). The reason for these differences is that the larvae are greatly affected by temperature, with higher temperatures generally accelerating larval development, especially during the third instar.

Pupae develop more quickly at cool temperatures and are on average $12 \mathrm{~mm}$ in length (Byrd \& Butler 1998) and the entire pupal stage can take approximately 16 days (Smith $\&$ Whitman 1992). Eclosion of adult S. haemorrhoidalis 
peaks in the morning, tapering off through the day with no eclosion occurring during nighttime (Madubunyi 1986).

Within two to nine days after adults emerge from the puparia, copulation occurs. There is no known courtship ritual for this species; males have no specialized ability to identify females of the species. In fact, it has been noted that males will copulate with other males and dead flies. Additionally, the same male has been observed mating with the same female multiple times suggesting that this species does not have a pheromone or other cues to detect previous insemination as has been observed for other Dipteran species. After insemination, eggs are retained in the female and require a minimum incubation of nine days with an average of 13 days before larviposition occurs (Madubunyi 1986). Females can lay 40 to 80 first instar larvae per reproductive cycle (Braverman et al. 1994).

\section{Medical and Economic Importance}

Sarcophaga haemorrhoidalis is of medical importance as it is one of 20 species known to cause gastrointestinal myiasis and the infestation of living tissue (Mullen \& Durden 2002). Myiasis can occur in livestock, including ungulates, which can result in economic loss. The main reason that S. haemorrhoidalis is a myiasis-causing species is due to its attraction to feces and preference to larviposit indoors (Byrd \& Castner 2001). Females are known to deposit larvae on mucus tissues of the rectum of immobile subjects (Braverman et al. 1994).

Myiasis most often occurs from ingesting contaminated food and infestations may be persistant if left untreated (Smith \& Whitman 1992). Myiasis is most likely to occur in areas with overcrowding and hygienic conditions that are substandard (Braverman et al. 1994) but can also occur in hospitals and nursing homes. Intestinal myiasis can be difficult to diagnose as the symptoms are similar to other intestinal diseases and disorders, and may also be asymptomatic. Diagnosis usually occurs when the presence of larvae in fresh stool samples is observed. Pain has been associated with the larval progression down the intestinal tract as the larvae use their buccal (mouth) hooks to move, which causes scratching along the intestinal lining. Itching and inflammation around the anal tissue is common in cases where larvae are deposited directly in the rectal area (Turhan et al. 2007).

Other forms of myiasis that can occur with S. haemorrhoidalis include nasal and aural infestations. Aural and nasal myiasis presents with a rancid, bloodstained pus, pain, and irritation in the infected tissue. Treatment consists of killing the maggots and removing them with forceps from the infested area (Braverman et al. 1994).

Adult S. haemorrhoidalis have been connected with the transmission of other disease organisms including Escherichia coli (Migula), Shigella dysenteriae (Shiga), Streptococcus spp., Salmonella spp., tapeworms, and even the virus responsible for polio (Smith \& Whitman 1992).

\section{Forensic Importance}

Sarcophaga haemorrhoidalis is particularly important to forensic entomology as it can be the first, or one of the first, arthropods to arrive at a corpse. The species is a strong flyer and has the ability to fly in inclement weather when other arthropod species are unable to fly. Sarcophaga haemorrhoidalis is most often associated with corpses found inside buildings, especially in the summer months in southeastern United States (Byrd \& Castner 2001). Like blow fly species, sarcophagid flies are also used to determine the postmortem interval (PMI) in death investigations (Byrd \& Butler 1998), and because their development cycle is short, they are the most useful for the first three to four weeks after death. This species has also been used for PMI estimations on severely burnt remains (Introna et al. 1997).

\section{Management}

Control of S. haemorrhoidalis is the same as for blow flies, house flies and other filth flies. Elimination of suitable food substrates by bagging trash and other decaying material and covering garbage containers will limit infestations by this species. Using mesh screens at doorways and windows as well as using air currents at speeds of $1500 \mathrm{ft} / \mathrm{min}(450 \mathrm{~m} /$ min) will also reduce access to indoor areas. Pesticides can be used to eliminate indoor $S$. haemorrhoidalis infestations using space sprays and residual sprays that are designed to control adult flies (Ebeling 2002).

\section{Selected References}

- Baker JR, Apperson CS, Arends JJ. (eds.). (1986). Flesh flies, Sarcophaga spp., Sarcophagidae, Diptera. Insect and related pests of man and animals. http://ipm.ncsu.edu/ AG369/notes/flesh_flies.html (7 June 2011).

- Braverman I, Dano I, Saah D, Gapany B. 1994. Aural myiasis caused by flesh fly larva, Sarcophaga haemorrhoidalis. Journal of Otolaryngology 23:204-205.

- Byrd JH. 1998-2011. Forensic entomology: insects in legal investigations. http://www.forensicentomology.com/ (8 June 2011). 
- Byrd JH, Butler JF. 1998. Effects of temperature on Sarcophaga haemorrhoidalis (Diptera: Sarcophagidae) development. Journal of Medical Entomology 35: 694-698.

- Byrd JH, Castner JL. (eds.) 2001. Forensic Entomology: the Utility of Arthropods in Legal Investigations. CRC Press. Boca Raton. 52 pp.

- Ebeling W. (2002). Pests on or near food. Urban Entomology. http://www.entomology.ucr.edu/ebeling/ebeling6. html\#flesh\%20flies (7 June 2011).

- Introna F, Campobasso CP, Fazio AD. 1997. Three case studies in forensic entomology from southern Italy. Journal of Forensic Sciences 43: 210-214.

- Madubunyi LC. 1986. Laboratory life history parameters of the red-tailed flesh fly, Sarcophaga haemorrhoidalis (Fallén) (Diptera: Sarcophagidae). Insect Science and its Application 7: 617-621.

- Mullen G, Durden L. 2002. Medical and Veterinary Entomology. Academic Press. San Diego. 597 pp.

- National Library of Medicine. (July 2006). Adult redtailed flesh fly (Sarcophaga haemorrhoidalis). Visible proof: forensic views of the body. http://www.nlm.nih.gov/ visibleproofs/galleries/exhibition/body_image_35.html (7 June 2011).

- Pape T. 1996. Catalogue of the Sarcophagidae of the World. (Insecta: Diptera). Memoirs of Entomology International 8: 1-558.

- Smith E, Whitman R. 1992. Flesh flies. pp. 6.4.1-6.4.4. In Field Guide to Structural Pests. National Pest Control Association. Fairfax, VA.

- Turhan V, Aydin AF, Eyigun CP, Araz E, Tanyuksel M, Pahsa A. 2007. An intestinal myiasis case of flesh fly (Sarcophaga haemorrhoidalis). The Anatolian Journal of Clinical Investigation 1:270-272. 